\title{
Protective effect of fermented Cyclopia intermedia against UVB-induced damage in $\mathrm{HaCaT}$ human keratinocytes
}

\author{
A-Rang $\mathrm{Im}^{1 \dagger}$, Sung Hum Yeon ${ }^{2 \dagger}$, Jung Seung Lee ${ }^{3}$, Key An Um³, Young -Joon Ahn ${ }^{2^{*}}$ and Sungwook Chae ${ }^{1 *}$
}

\begin{abstract}
Background: The fermented leaves and stems of Cyclopia intermedia are used to brew honeybush tea, a herbal tea indigenous to South Africa. The aim of this study was to evaluate the protective effect of fermented honeybush extracts (FH ex) and scale-up fermented honeybush extracts (SFH ex) against ultraviolet B (UVB)-induced damage in $\mathrm{HaCaT}$ keratinocytes. To this end, we examined UVB-induced cell viability, antioxidant enzymes, and inflammatory mediators in HaCaT cells.

Methods: UVB significantly decreased HaCaT cell viability, whereas FH ex and SFH ex did not exhibit cytotoxic effects and increased the viability of the HaCaT cells. To further investigate the protective effects of $\mathrm{FH}$ ex on UVB-induced oxidative stress in HaCaT cells, the activities of superoxide dismutase (SOD), catalase (CAT), matrix metalloproteinases (MMPs), pro-inflammatory cytokines and skin barrier function in terms of involucrin, filaggrin, and loricrin were analyzed.

Results: UVB-induced treatment reduced the activity of antioxidant enzymes and skin barrier function, while FH ex or SFH ex increased their activity. These results suggest that FH ex exerted cytoprotective activity against UVB-induced oxidative stress in $\mathrm{HaCaT}$ cells through stimulation of antioxidant enzymes activities. Furthermore, FH ex and SFH ex suppressed the UVB-induced expression of inflammatory mediators, such as IL-1 $\beta$, IL-6, and IL-8, at mRNA level together with down regulation of matrix metalloproteinase (MMPs). In addition, FH ex and SFH ex reversed the phosphorylation of mitogen-activated protein kinase (MAPK) induced by UVB-irradiation. Notably, FH ex and SFH ex markedly inhibited UVB-induced activation of ERK, p38, and JNK. Thus, this agent exhibits anti-oxidative and -inflammatory effects via lowering ROS production, suppressing p38, ERK, and JNK activation, and down-regulating expression of MMPs.
\end{abstract}

Conclusions: These findings suggest that FH ex and SFH ex can be used as a skin anti-photoaging agent.

Keywords: Fermented honeybush extracts, Scale-up fermented honeybush extracts, $\mathrm{HaCaT}$ keratinocytes, Matrix metalloproteinase (MMP), Mitogen-activated protein kinase (MAPK), Reactive oxygen species (ROS)

\section{Background}

Skin aging has been shown to an intrinsic component and a variable environmental component, termed photoaging. Clinically, photodamaged skin is characterized by loss of elasticity, increased roughness and dryness, irregular pigmentation, and deep wrinkling [1]. Many of the skin

\footnotetext{
* Correspondence: yjahn@snu.ac.kr; kendall@kiom.re.kr

${ }^{\dagger}$ Equal contributors

2Biomodulation Major. Department of Agricultural Biotechnology, Seoul National University, Seoul 157-742, Republic of Korea

${ }^{1}$ KM Convergence Research Division, Korea Institute of Oriental Medicine,

Daejeon 305-811, Republic of Korea

Full list of author information is available at the end of the article
}

changes commonly associated with aging, such as changes in pigmentation, sallowness, and deep wrinkling, are actually the result of sun exposure [2]. In sun-exposed areas, biological processes are superimposed on specific changes that occur in response to UV radiation, including massive elastosis and collagen degeneration [3]. It is important to investigate the effects of biological aging caused by environmental factors, such as exposure to the sun.

Human skin is directly exposed to the air, solar radiation, environmental pollutants, and other mechanical and chemical insults, which are capable of inducing the 
generation of free radicals, in addition to the reactive oxygen species (ROS) produced by during metabolism $[4,5]$. In extrinsic skin aging, the skin suffers additional free radical damage caused by exogenous factors, such as UV exposure; UVA/UVB-radiation contributes to skin aging and photocarcinogenesis [1]. These biological effects of UV-radiation are based on light absorption in chromophores and the subsequent conversion of this energy in chemical reactions. UVB interacts with cellular chromophores and photosensitizers, and the ROS so generated leads to DNA damage and activation of cytoplasmic signal transduction pathways that are related to growth, differentiation, replicative senescence, and connective tissue degradation [2]. Increased ROS generation can overwhelm the antioxidant defense mechanism, resulting in oxidative stress and photodamage of macromolecules and plasma membrane components in the skin [6].

UVB-induced ROS activates matrix metalloproteinases (MMPs) in both the epidermis and dermis, and degrades collagen and elastin in the dermal extracellular matrix [7]. Skin fibroblasts produce MMP-1 in response to UVB irradiation, and keratinocytes play a major role in this process through an indirect paracrine mechanism involving the release of epidermal cytokines after UVB irradiation [8]. UV-induced MMP-1 initiates collagen breakdown by cleaving fibrillar collagen type I and III [9].

UVB exposure of the skin stimulates inflammatory responses via upregulation of pro-inflammatory cytokines, such as tumor necrosis factor- $\alpha$ (TNF- $\alpha)$, interleukin- $1 \beta$ (IL-1 $\beta)$, IL-6, and IL-8 [10]. UVB-induced cell damage leads to activation of ROS-sensitive signaling pathways, such as the mitogen-activated protein kinase (MAPK) pathway [11]. The MAPKs are a family composed of extracellular signal-regulated kinase (ERK), c-Jun $\mathrm{NH}_{2}$ terminal kinase (JNK), and p38 MAPK.

Fragments of collagen, a main constituent of the extracellular matrix (ECM), released as a result of MMPinduced collagen cleavage, are bioactive and participate in the regulation of the fibroblast phenotype during photoaging [12]. Collagen has been used as a functional ingredient in skin products due to its efficacy in moisturizing and enhancing elasticity. Moreover, involucrin, filaggrin, and loricrin are major proteins that play an important role in formation of the epidermal skin barrier and skin hydration [13].

$\mathrm{H}_{2} \mathrm{O}_{2}$ is converted to $\mathrm{H}_{2} \mathrm{O}$ and $\mathrm{O}_{2}$ either by catalase (CAT), located in the peroxisome as well as in the cytoplasm [14]. In addition to superoxide dismutase (SOD) is another important endogenous antioxidant enzyme that fights against ROS-induced oxidative stress in living organs [15].

The fermented leaves and stems of Cyclopia intermedia, or honeybush, is used as a herbal tea indigenous to South Africa [16]. Honeybush is an evergreen shrub belonging to
Melianthaceae, which is only distributed in a narrow mountain ridge region along the east-west coast of the Cape region of South Africa, and is highly similar to Rooibos [17]. In previous studies, aqueous extracts of fermented and unfermented honeybush tea have been shown to possess antimutagenic activity against 2-acety laminofluorene and aflatoxin B1-induced mutagenesis as well as chemoprotective properties against cancer [18]. In our previous study, fermented honeybush extracts (FH ex) showed stronger activity on the inhibition of wrinkle as compared to non-fermented honeybush extracts [19]. FH ex was studied as lab-scale in terms of nonclinical trial using in vitro model. Lab-scale study is giving information for subsequent research for larger scale. FH ex was evaluated as important step in finding feasibility for clinical trial. After developing FH ex in terms of safety and manufacturing cost which is meaningful results for potent clinical intervention, scale-up fermented honeybush extracts (SFH ex) was established.

In this study, we investigated the signaling pathway accounting for the cytoprotective effects of $\mathrm{FH}$ ex and $\mathrm{SFH}$ ex against UVB-induced oxidative stress in $\mathrm{HaCaT}$ cells. We found that $\mathrm{FH}$ ex or $\mathrm{SFH}$ ex protected cells against UVB-induced oxidative stress through stimulation of antioxidant enzyme activities. Furthermore, FH ex and SFH ex suppressed UVB-induced expression of inflammatory mediators, such as IL-1 $\beta$, IL-6, and IL-8, at mRNA level, suppressing p38, ERK and JNK activation together with MMPs expression.

\section{Methods \\ Materials}

Cyclopia intermedia was purchased from Rooibos.Ltd (www.rooibosltd.co.za), and dried samples (1.0 kg) were extracted with distilled water $(8 \mathrm{~L})$ two times under reflux for $1 \mathrm{~h}$. The filtrate was evaporated in vacuo to afford the extract (200 g). To prepare fermented honeybush (FH ex), the method was slightly modied from the previous study [19]. To prepare FH ex, $1.0 \%$ of lactic acid bacteria (Streptococcus thermophilus) was inoculated in $100 \mathrm{~mL}$ of water with $5 \%$ of the honeybush extract, $12.6 \%$ of whole milk powder, and $3 \%$ of sucrose. The mixture was fermented in a $37{ }^{\circ} \mathrm{C}$ incubator for $24 \mathrm{~h}$. For the preparation of scale-up fermented honyebush (SFH ex), honeybush was extracted with water 2 times under reflux and then filtered. The filtrate was evaporated to give 20 brix extract. To prepare SFH ex, $10 \%$ of lactic acid bacteria (Streptococcus thermophilus) was inoculated in $0.5 \%$ of whole milk powder with $3 \%$ of lactose, $23 \%$ of the honeybush extract (20 brix), and $63.5 \%$ of purified water. The mixture was fermented in a $37{ }^{\circ} \mathrm{C}$ incubator for $48 \mathrm{~h}$. After sterilization of fermented mixture, final product was obtained by mixing dextrin (DE12) and spray drying. DMEM media and fetal bovine serum (FBS) were purchased from 
Gibco BRL (Grand Island, NY). A CellTiter Aqueous One Solution Cell Proliferation Assay kit (MTS) was purchased from Promega Co. (Madison, WI). Human total MMP-1 and -9 ELISA kits were obtained from R\&D Systems, Inc. (Minneapolis, MN).

\section{Cell culture and UVB irradiation}

$\mathrm{HaCaT}$ cells, an immortalized non-tumorigenic human keratinocyte cell line obtained from Huons Co. Ltd, (Gyeonggi-do, Korea), were maintained in Dulbecco's modified Eagle's medium (DMEM) supplemented with $10 \%$ fetal bovine serum and $1 \%$ antibiotics at $37^{\circ} \mathrm{C}$ and $5 \% \mathrm{CO}_{2}$ in a humidified incubator. $\mathrm{HaCaT}$ cells were seeded and allowed to adhere for $24 \mathrm{~h}$. The cells were treated with various concentrations of $\mathrm{FH}$ ex and SFH ex and exposed to UVB radiation at a dose of $20 \mathrm{~mJ} /$ $\mathrm{cm}^{2}$. Cells that received no pretreatment and were not exposed to UVB irradiation served as the control.

\section{Cell viability assay}

$\mathrm{HaCaT}$ cells $\left(1 \times 10^{4}\right)$ were seeded in 96-well culture plates and treated with various concentrations of $\mathrm{FH}$ ex and SFH ex for $24 \mathrm{~h}$. Before UVB treatment, the cell culture medium was replaced by phosphate-buffered saline (PBS) and exposed to $20 \mathrm{~mJ} / \mathrm{cm}^{2}$ of UVB. Immediately after UVB irradiation, cell viability was assessed after $1 \mathrm{~h}$ by reduction of [3-(4,5-dimethylthiazol-2-yl)-5(3-carboxymethoxyphenyl)-2-(4-sulfophenyl)-2H-tetrazo lium, inner salt (MTS) to formazan, according to the manufacturer's instruction. Samples were then assayed at $490 \mathrm{~nm}$ using a microplate fluorimeter (Molecular Devices, Sunnyvale, CA).

\section{Antioxidant enzymes activities}

SOD and CAT activity was measured using a colorimetric assay kit (Cayman Chemical Co., Ann Arbor, MI) according to the manufacturer's protocol. Cells were treated with FH ex for $24 \mathrm{~h}$. After UVB exposure, cells were homogenized in cold lysis buffer. The absorbance was measured at $450 \mathrm{~nm}$ to determine SOD activity, and at $540 \mathrm{~nm}$ to determine CAT activity, by using a plate reader (Molecular Devices, Sunnyvale, CA).

\section{Determination of MMP-1 and-9 secretions by ELISA}

After UVB irradiation, matrix metalloproteinases-1 and -9 levels in the culture media of $\mathrm{HaCaT}$ cells $\left(5 \times 10^{4}\right)$ were determined using human total MMP-1 and -9 ELISA kits according to the manufacturer's instructions. HaCaT cells were seeded in 96-well plates and treated with FH ex and SFH ex. After exposure to UVB, the culture supernatant was collected and centrifuged at 13,000 rpm for $5 \mathrm{~min}$. The levels of MMP-1 and MMP-9 in culture supernatants were quantified by colorimetric analysis.

\section{Quantitative Real-time PCR assays}

Total RNA was extracted from each sample treated with UVB using TRIzol reagent (Invitrogen, Carlsbad, CA). Real-time PCR was performed using TaqMan Gene assays (Applied Biosystems, Foster City, CA) specific for the genes encoding MMP-1, MMP-9, tissue inhibitor of metalloproteinase (TIMP), involucrin, filaggrin, loricrin, IL-1 $\beta$, IL-6, IL-8, on a QuantStudio ${ }^{\text {TM }} 6$ Flex Real-Time PCR systems. Relative amounts of cDNA were calculated by the relative quantification $(\Delta \Delta \mathrm{Ct})$ method. Each sample was run in triplicate and the gene encoding $\beta$-actin was used as a control to normalize for differences in the amount of total RNA in each sample.

\section{Western blot}

Protein was extracted from $\mathrm{HaCaT}$ cells. Twenty microgram of protein lysates from each sample were electrophoresed on a $10 \%$ sodium dodecyl sulfate (SDS)polyacrylamide gel and were then transferred to PVDF membranes. Membranes were blocked for $1 \mathrm{~h}$ at room temperature in $5 \%$ skim milk solution. Blots were incubated overnight at $4{ }^{\circ} \mathrm{C}$ with a 1:1000-diluted monoclonal antibody. The blots were washed three times for
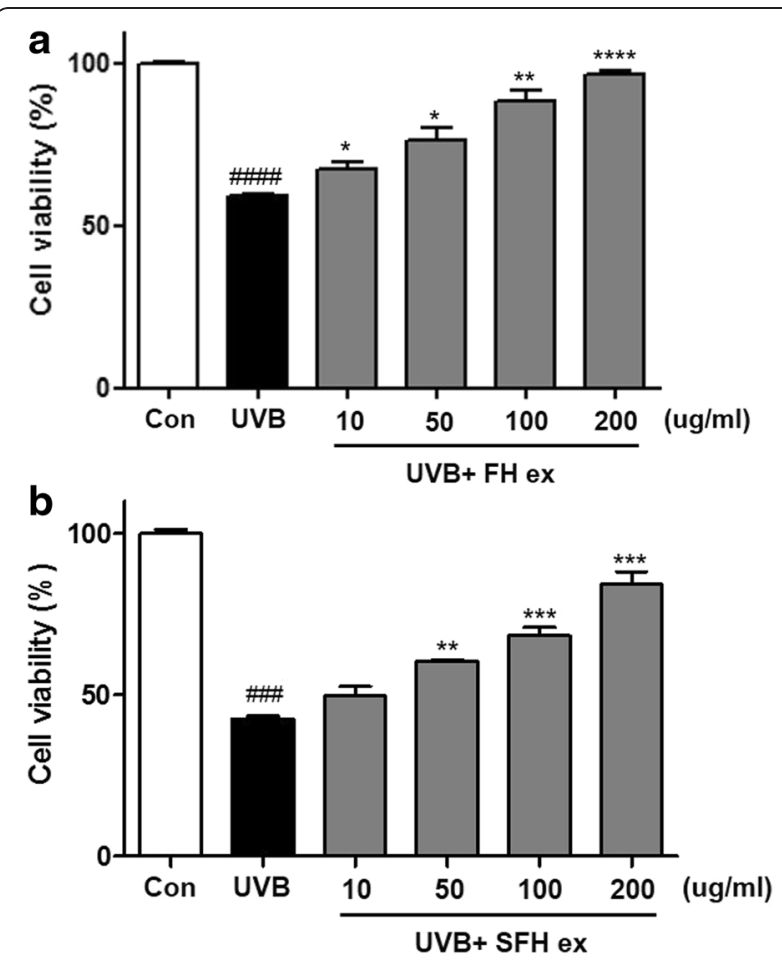

Fig. 1 Cell viability of human keratinocytes after UVB exposure. HaCaT cells were pretreated with various concentrations of (a) fermented honeybush extract (FH ex) and (b) scale up fermented honeybush extract (SFH ex) for $24 \mathrm{~h}$, followed by UVB irradiation. Data are reported as percentages of the control group. \#\#\# $P<0.0001$ and \#\#\# $P<0.001$ as percentages of the control group. ${ }^{* * *} P<0.0001,{ }^{* * *} P<0.001$, ${ }^{*} P<0.01$ and ${ }^{*} P<0.05$ vs UVB vehicle group 


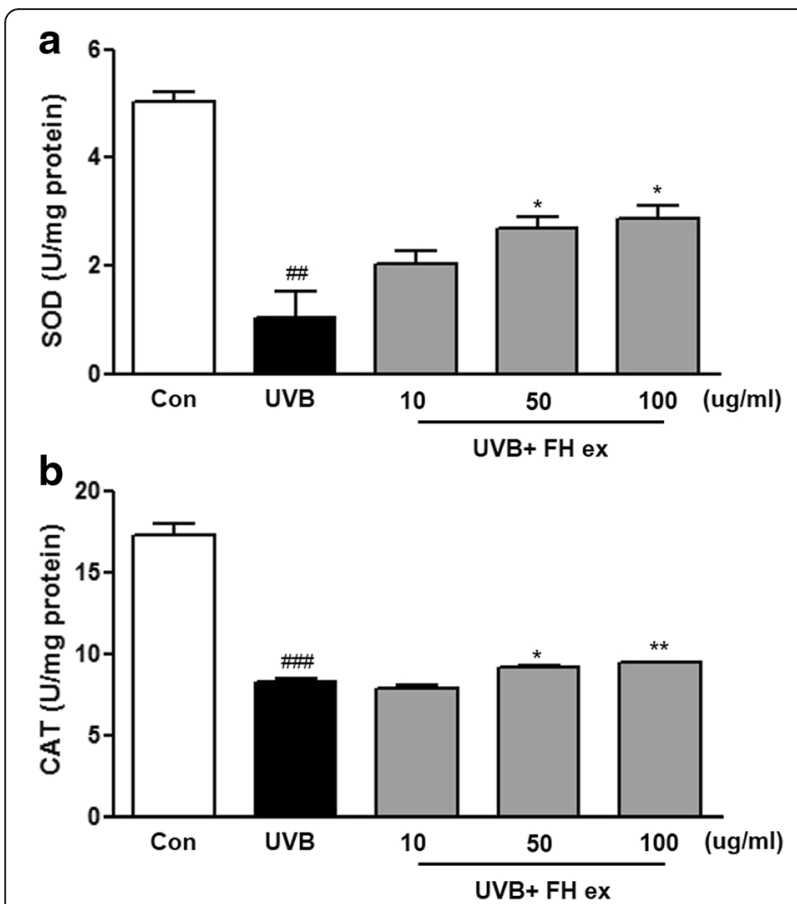

Fig. 2 Effects of FH ex on the activity of (a) SOD, and (b) CAT in HaCaT cells exposed to UVB. \#\#\# $P<0.001$, and \#\# $P<0.01$ vs control group. ${ }^{* *} P<0.01$ and ${ }^{*} P<0.05$ vs UVB vehicle group
10 min each time with Tris-buffered Saline (TBST). The membranes were then incubated for $2 \mathrm{~h}$ with secondary antibody. Proteins were detected using an enhanced chemiluminescence.

\section{Statistics}

Results were compared using Tukey's multiple comparison test, where a $p<0.05$ was considered statistically significant. GraphPad Prism 5 was used for statistical analyses.

\section{Results}

Protective effects of FH ex and SFH ex against UVB-induced $\mathrm{HaCaT}$ cell damage

We investigated the effect of $\mathrm{FH}$ ex and $\mathrm{SFH}$ ex on the proliferation of $\mathrm{HaCaT}$ cells after exposure to UVB. Cell viability was reduced to $59.14 \%$ by UVB irradiation in the absence of FH ex, but cell proliferation was increased up to 96.78 \% (Fig. 1a) in its presence. Also, in SFH ex group, cell proliferation was increased up to 84.07 \% (Fig. 1b) in its presence.

\section{Effects of $\mathrm{FH}$ ex on the activity of antioxidant enzymes in UVB-induced $\mathrm{HaCaT}$ cells}

To investigate whether the radical scavenging activity of FH ex was mediated by antioxidant enzymes, the activities of antioxidant enzymes were examined in $\mathrm{HaCaT}$ cells after UVB exposure. SOD activity decreased to $0.7 \mathrm{U} / \mathrm{ml}$ in UVB-induced cells compared to the untreated control (Fig. 2a), SOD activity was enhanced by FH ex treatment

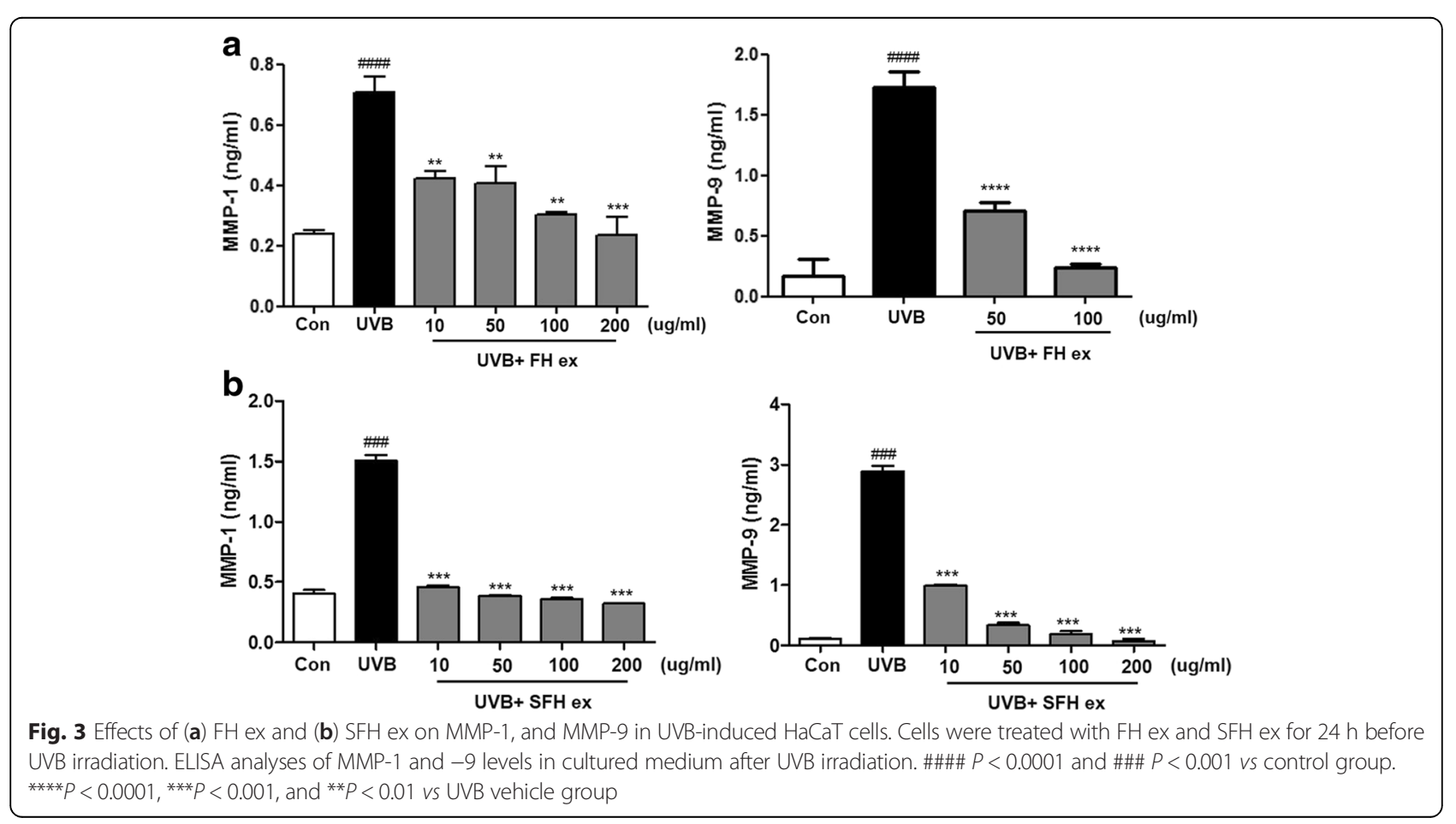


in a dose-dependent manner. Furthermore, in comparison with the control group, the activities of CAT in the UVBinduced group were decreased, but treatment with $\mathrm{FH}$ ex increased CAT activities (Fig. 2b). These results revealed that $\mathrm{FH}$ ex could protect the activities of antioxidant enzymes that scavenge free radicals and thereby could further inhibit UVB-induced oxidative stress.

\section{Effects of FH ex and SFH ex on UVB-induced secretion of MMP-1 and MMP-9}

We evaluated the effect of FH ex and SFH ex on UVBinduced MMP expression in $\mathrm{HaCaT}$ cells. UVB irradiation of $\mathrm{HaCaT}$ cells resulted in a marked increase in MMP-1 and -9 levels (Fig. 3). ELISA analysis revealed that FH ex and SFH ex treatment reduced MMP-1 and -9 protein levels in the culture media of $\mathrm{HaCaT}$ cells in a dosedependent manner.
Effects of FH ex and SFH ex on UVB-induced secretion of MMP, TIMP, and procollagen

The mRNA expression of MMP-1 and TIMP genes in $\mathrm{HaCaT}$ cells after UVB irradiation was measured by RTPCR (Fig. 4). UVB caused a decrease in TIMP-1 mRNA levels, whereas pretreatment with $\mathrm{FH}$ ex and $\mathrm{SFH}$ ex inhibited this decrease. Western blotting demonstrated that UVB irradiation reduced the level of procollagen expression compared with the control group (Fig. 4), and pretreatment with FH ex and SFH ex prevented this decrease.

Effects of FH ex and SFH ex on involucrin, filaggrin, and loricrin levels in UVB- induced $\mathrm{HaCaT}$ cells

We showed that the expression of involucrin, filaggrin, and loricrin was decreased by UVB. As shown in Fig. 5, mRNA expression of involucrin, filaggrin, and loricrin in

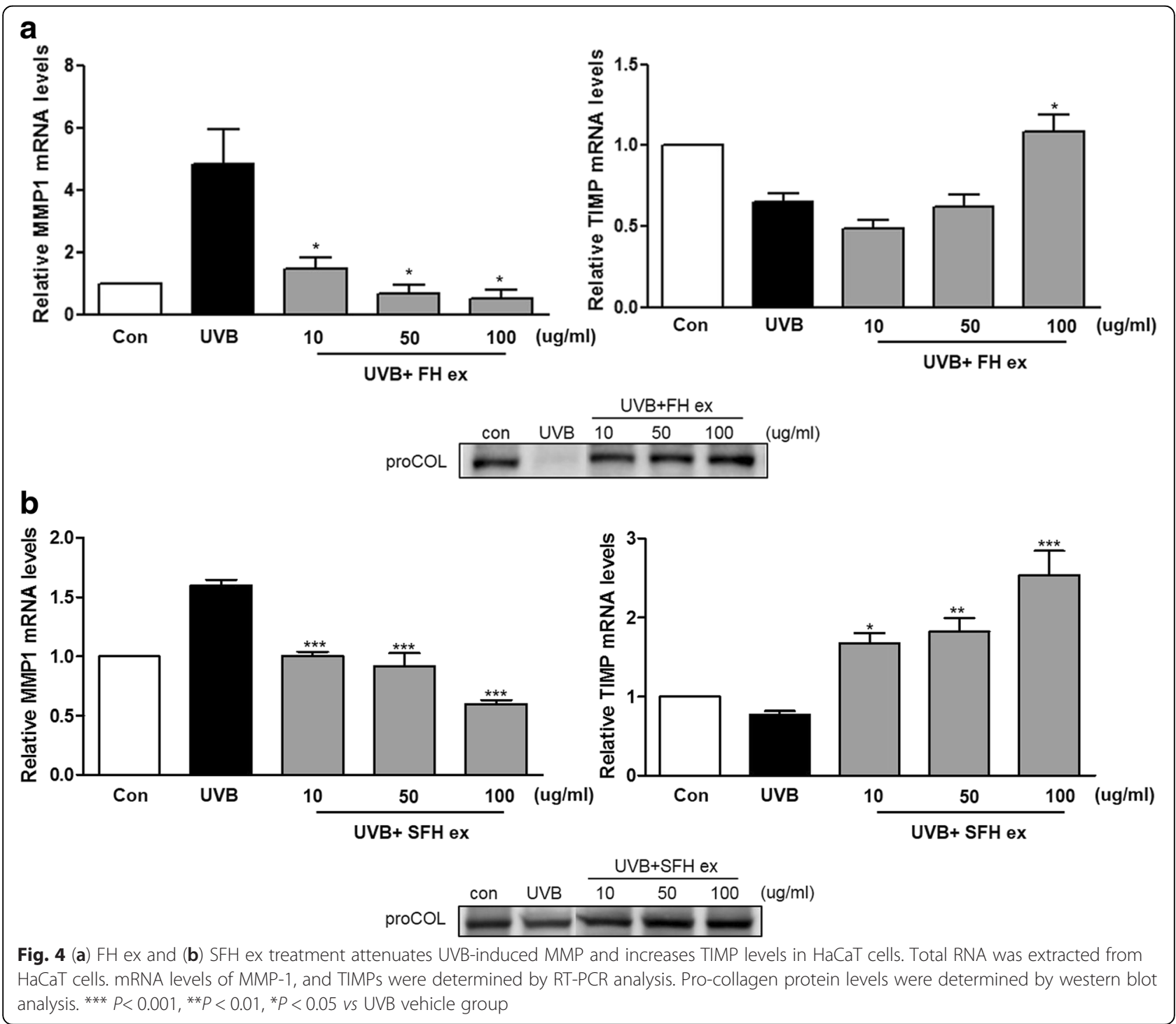



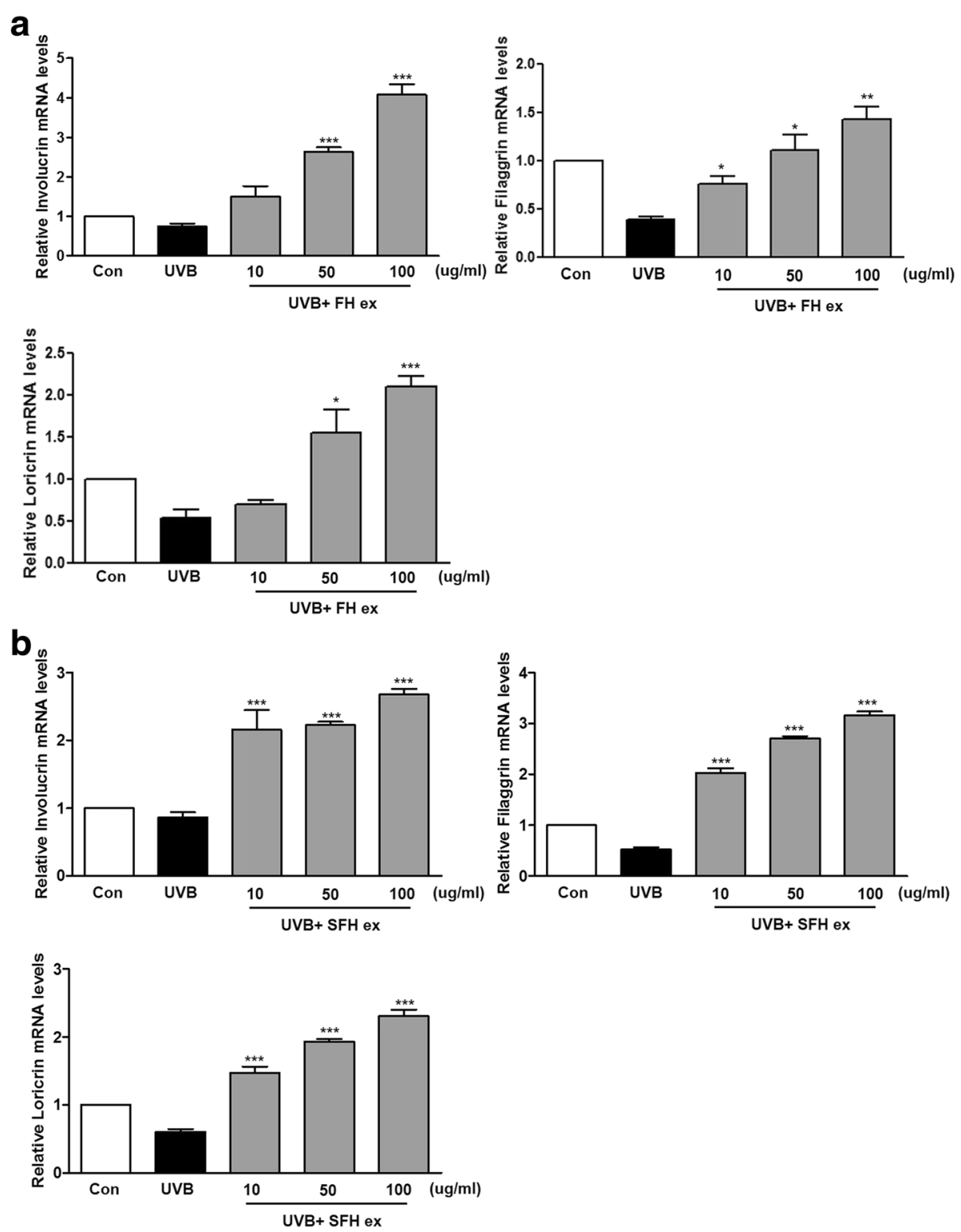

Fig. 5 Effects (a) FH ex and (b) SFH ex on involucrin, filaggrin, and loricrin levels in UVB-induced HaCaT cells. ${ }^{* * *} P<0.001$, ${ }^{* *} P<0.01$, and ${ }^{*} P<0.05$ vs UVB vehicle group

UVB-induced cells treated with FH ex and SFH ex was increased, as compared to UVB exposed cells.

Effects of FH ex and SFH ex on IL-1 $\beta$, IL-6, and IL-8 levels in UVB-induced HaCaT cells

To evaluate the effects of FH ex and SFH ex on the UVB-induced production of inflammatory mediators, cells were treated with FH ex and SFH ex for 24 h prior to UVB exposure. UVB significantly increased the levels of IL-1 $\beta$, IL- 6 , and IL- 8 mRNA as compared with those in the normal cells (Fig. 6), but $\mathrm{FH}$ ex and $\mathrm{SFH}$ ex inhibited this elevation. These results suggested that the protective effect of $\mathrm{FH}$ ex and SFH ex may be partly associated with inhibition of the release of proinflammatory cytokines in response to UVB induction.

Effects of FH ex and SFH ex on phosphorylation of MAPKs in UVB-induced HaCaT cells

We examined whether FH ex and SFH ex could suppress UVB-induced phosphorylation of MAPKs, including ERK, MEK, p38, and JNK. As shown in Fig. 7, irradiation of UVB resulted in phosphorylation of ERK, MEK, p38, and 

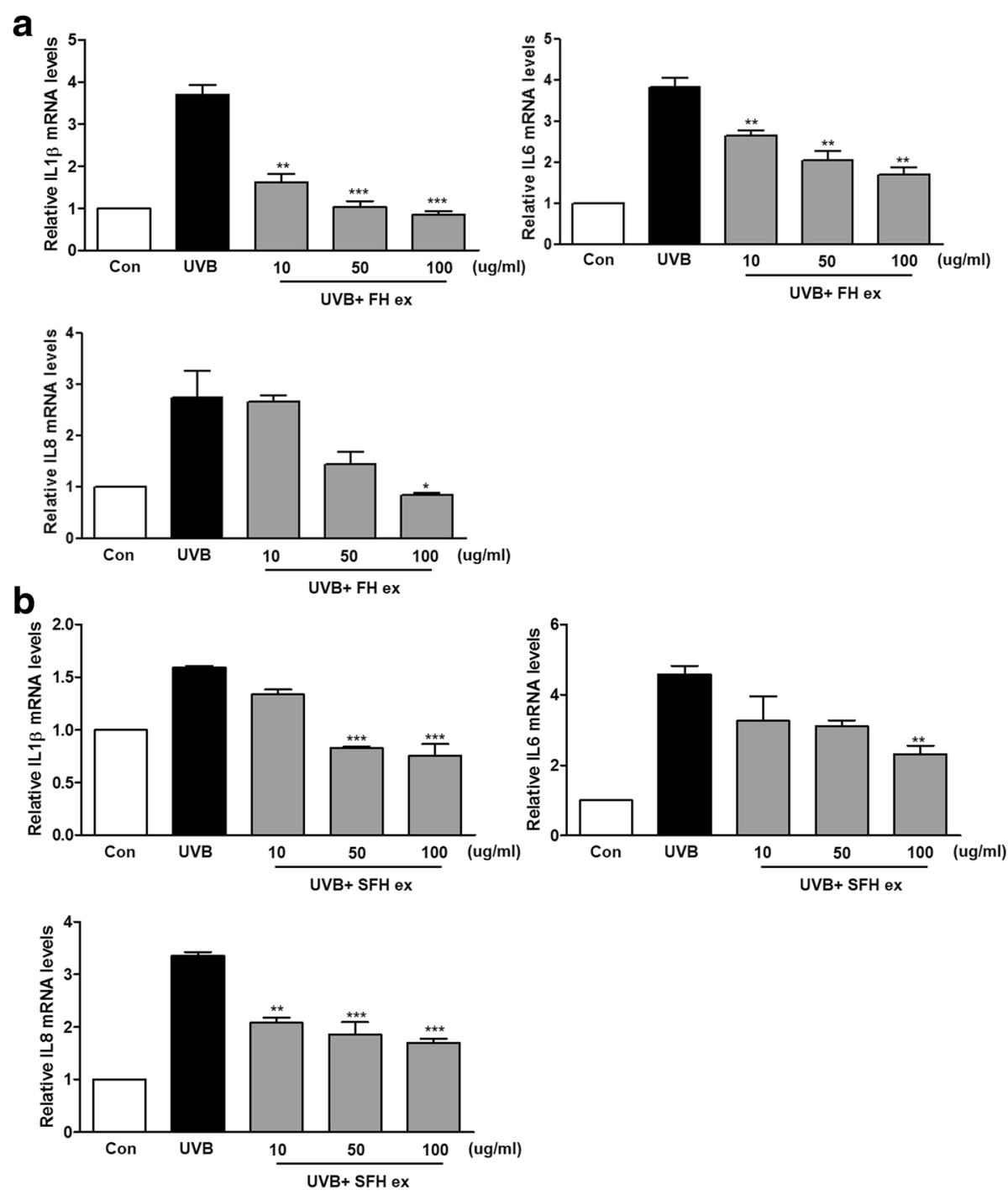

Fig. 6 Effects (a) FH ex and (b) SFH ex on the pro-inflammatory cytokines of UVB-induced HaCaT cells. IL-1 $\beta$, IL-6, and IL-8 secretion mRNA were determined by RT-PCR analysis. ${ }^{* *} P<0.001,{ }^{* *} P<0.01$, and ${ }^{*} P<0.05$ vs UVB vehicle group

JNK, whereas treatment of cells with FH ex and SFH ex prior to UVB irradiation inhibited the UVB-mediated phosphorylation of these MAPKs.

\section{Discussion}

Herbal ingredients are used for dermatological purposes, as oral dietary supplements or are incorporated into topical formulations [20]. Their potential antioxidant and anti-inflammatory benefits may prove beneficial for a number of conditions that dermatologists routinely treat, such as rosacea, photoaging, and skin cancer [21]. For example, topical application of green and white tea extracts can reduce some of the detrimental immunomodulatory effects of photodamage [22]. FH ex was prepared for the evaluation of feasibility to examine the scale-up study. Pilot studies are mainly focused on the efficacy rather than safety and production cost, however it can inform modifications for the design of larger scale study. A pilot study provides opportunity to enhance data integrity and the protection of human subjects in terms of toxicology [23]. FH ex used in our paper was studied as pilot scale prior to clinical research manufactured in a larger facility. As our data showed FH ex exerted cytoprotective activity against UVB-induced oxidative stress in $\mathrm{HaCaT}$ cells, FH ex was modified for human clinical trial and commercial requirements. After evaluation of SFH ex regarding toxicology studies using SD rat and beagle in GLP facility (data not shown), the SFH ex was established and tested for skin damage. In our results, biological activity regarding cytoprotective effects of SFH ex showed 


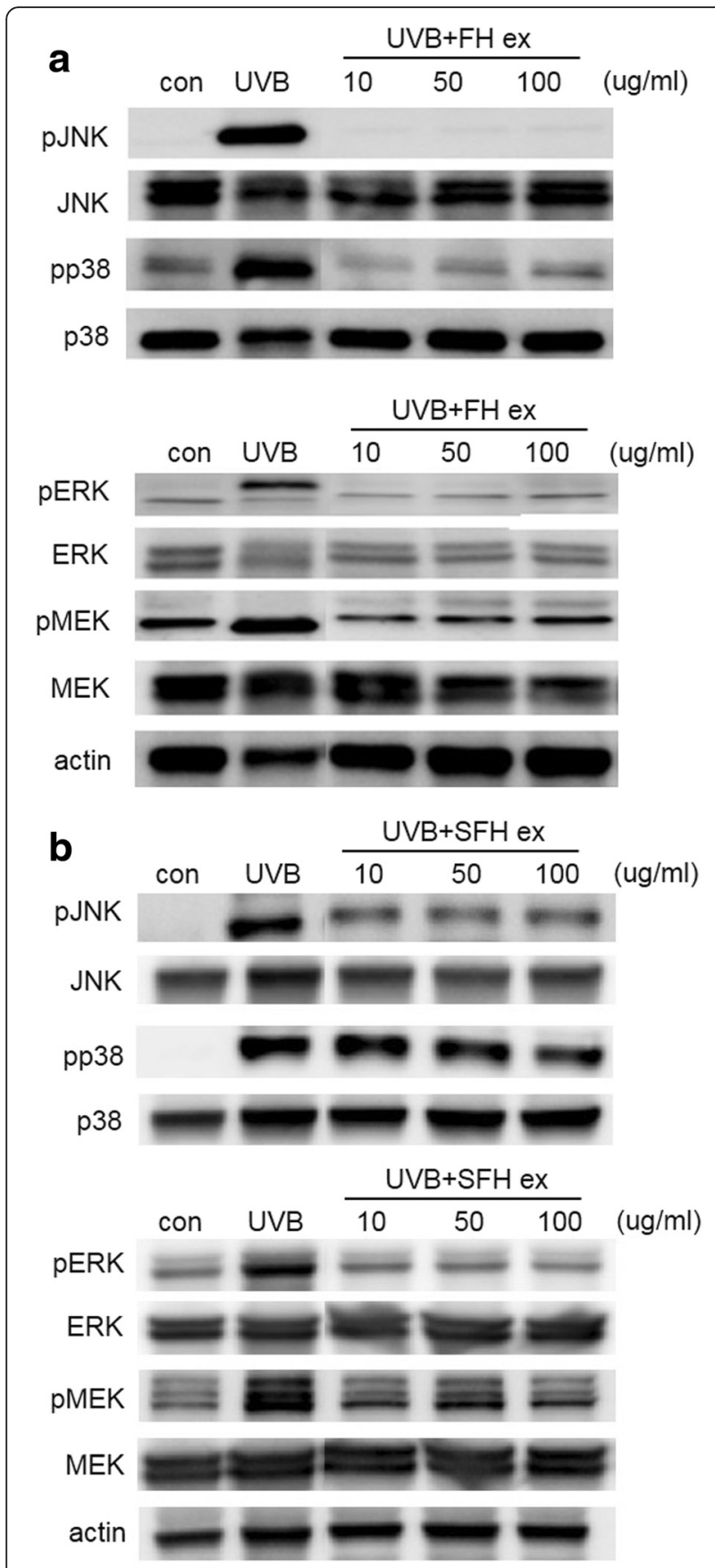

Fig. 7 Inhibitory effects of (a) FH ex and (b) SFH ex on UVB-induced phosphorylation of ERK, MEK, JNK, and p38 in HaCaT cells. PhosphoERK, phosphor-MEK, phospho-p38, phospho-JNK, and $\beta$-actin protein levels were determined by western blot analysis

similar level as $\mathrm{FH}$ ex to fit novel intervention for clinical trials. Taken together SFH ex can be applied for clinical trials to reduce the risk of toxicity and manufacturing cost.

Human skin is equipped with a network of antioxidant enzymes that play an important role in the balance of intracellular ROS levels [24]. Exposure of human or mouse skin to UVB radiation results in excessive generation of ROS that overwhelms the antioxidant defense system, resulting in oxidative stress [4]. ROS in the biological system have been linked to skin cancers, DNA damage, cutaneous aging, and many inflammatory disorders. In a previous study, it has been shown that UV light induced decreases in the antioxidant enzymes CAT and SOD [25]. In this study, FH ex could protect the activities of antioxidant enzymes that scavenge free radicals such as SOD and CAT and thereby could further inhibit UVB-induced oxidative stress.

MMPs are a large family of degradative enzymes that play important roles in tissue destruction during pathological processes, such as arthritis, skin aging, tumor invasion, and metastasis [26]. MMPs degrade collagen fibers in the skin, which form an important part of the connective tissue that is involved in the maintenance of dermal strength and elasticity [27]. And TIMPs are primary enzymes involved in the regulation of collagen metabolism; TIMP-1 inhibits the activity of MMPs that relative to TIMPs suggests that MMPs activities are elevated in photodamaged skin resulted in breakdown of collagen [28]. Irradiation of human skin with even a single dose of UV light has been shown to increase the activities of MMPs, which has been associated with significant degradation of collagen fibers [29]. A decrease in procollagen expression caused by repeated UV irradiation is considered to be a cause of photoaging [30]. The present study found that treatment of $\mathrm{HaCaT}$ cells with FH ex and SFH ex prior to UVB irradiation significantly decreased MMP-1 and MMP-9 expression, and increased that of TIMP-1

Filaggrin and profilaggrin are essential for maintaining homeostasis in the epidermis and filaggrin also undergoes further processing in the upper stratum corneum to release free amino acids that assist in water retention [31]. Involucrin, a differentiation marker normally expressed by irreversibly differentiated keratinocytes in the stratum corneum [32]. Filaggrin, involucrin, and loricrin are important source for maintaining skin moisture [33]. In a previous study, downregulation of filaggrin and loricrin have been shown to be involved in skin reconstructed in vitro after UVB exposure [34]. In this study, mRNA expression of involucrin, filaggrin, and loricrin in UVBinduced cells treated with FH ex and SFH ex was increased, as compared to UVB exposed cells. These results showed that $\mathrm{FH}$ ex and $\mathrm{SFH}$ ex have a skin hydration effects.

Keratinocytes respond to the major changes in inflammation and immunomodulation observed after UVB exposure, at least in part via UVB-induced expression of inflammatory enzymes and release of pro-inflammatory mediators [35]. Chronic UVB irradiation was shown to increase the production of some pro-inflammatory cytokines, such as TNF- $\alpha$, IL-1 $\beta$, IL- 6 , and IL- 8 , leading to cell death in $\mathrm{HaCaT}$ cells [36]. We here examined the effect of 
FH ex and SFH ex on UVB-induced pro-inflammatory cytokine production in $\mathrm{HaCaT}$ cells and found that the inhibitory effect of $\mathrm{FH}$ ex and SFH ex on the production of inflammatory mediators was accompanied by reduced mRNA expression levels of IL-1 $\beta$, IL-6, and IL-8.

ROS are known to play a role in UV-induced skin damage and aging. Exposure to UV irradiation induces the production of ROS in skin cells; this ROS activates cellular signaling pathways that activate kinases such as p38, JNK, and MAPK. Previous studies have shown activation of the three MAP kinases, ERK, JNK, and p38, within $1 \mathrm{~h}$ of acute UV radiation [37]. We observed that FH ex and SFH ex inhibited UVB-induced activation of JNK, p38, pMEK and ERK.

\section{Conclusion}

In conclusion, these agents exhibit anti-oxidative and inflammatory effects that are mediated by lowering ROS production, suppressing p38, ERK, MEK and JNK activation, and down-regulating expression of MMPs. These findings suggest that FH ex and SFH ex can be used as a skin anti-photoaging agent.

\begin{abstract}
Abbreviations
CAT, catalase; DMEM, Dulbecco's modified eagle medium; FH ex, fermented honeybush extracts; MAPK, mitogen-activated protein kinase; MMPs, matrix metalloproteinase; mRNA, messenger RNA; PBS, phosphate-buffered saline; PVDF, polyvinylidene difluoride; qRT-PCR, quantitative real-time polymerase chain reaction; RNA

ribonucleic acid; ROS, reactive oxygen species; SFH ex, scale-up fermented honeybush extracts; SOD, superoxide dismutase; TBST, Tris-buffered Saline; TIMP, tissue inhibitor of metalloproteinase: UVB, ultraviolet B.
\end{abstract}

\section{Acknowledgements}

This study was supported by grants (K15301) from the Korean Institute of Oriental Medicine and Innopolis foundation (14DDI094).

\section{Availability of data and material}

The data and materials of this article are included within the article

\section{Competing interests}

The authors declare that there is no conflict of interests.

\section{Consent for publication}

Not applicable.

\section{Ethics approval and consent to participate}

Not applicable.

\footnotetext{
Author details

'KM Convergence Research Division, Korea Institute of Oriental Medicine, Daejeon 305-811, Republic of Korea. ${ }^{2}$ Biomodulation Major. Department of Agricultural Biotechnology, Seoul National University, Seoul 157-742, Republic of Korea. ${ }^{3}$ Research Center, Huons Co. Ltd, 55 Hanyangdaehak-ro,

Sangrok-gu, Ansan, Gyeonggi-do 426-791, Republic of Korea.

Received: 2 December 2015 Accepted: 14 July 2016

Published online: 29 July 2016

\section{References}

1. Kohl E, Steinbauer J, Landthaler M, Szeimies RM. Skin ageing. J Eur Acad Dermatol Venereol. 2011;25(8):873-84.

2. Helfrich $\mathrm{YR}$, Sachs DL, Voorhees JJ. Overview of skin aging and photoaging. Dermatol Nurs. 2008;20(3):177-83. quiz 184.
}

3. Bernstein EF, Chen YQ, Tamai K, Shepley K, Resnik KS, Zhang H, et al. Enhanced elastin and fibrillin gene expression in chronically photodamaged skin. J Invest Dermatol. 1994;103(2):182-6.

4. Poljšak B, Dahmane R. Free radicals and extrinsic skin aging. Dermatol Res Pract. 2012;2012:135206.

5. Waris $G$, Ahsan $H$. Reactive oxygen species: role in the development of cancer and various chronic conditions. J Carcinog. 2006;5:14.

6. Cho HS, Lee MH, Lee JW, No KO, Park SK, Lee HS, et al. Anti-wrinkling effects of the mixture of vitamin C, vitamin E, pycnogenol and evening primrose oil, and molecular mechanisms on hairless mouse skin caused by chronic ultraviolet B irradiation. Photodermatol Photoimmunol Photomed. 2007;23(5):155-62

7. Pandel R, Poljšak B, Godic A, Dahmane R. Skin photoaging and the role of antioxidants in its prevention. ISRN Dermatol. 2013;2013:930164.

8. Brenneisen P, Sies H, Scharffetter-Kochanek K. Ultraviolet-B irradiation and matrix metalloproteinases: from induction via signaling to initial events. Ann N Y Acad Sci. 2002;973:31-43.

9. Quan T, Qin Z, Xia W, Shao Y, Voorhees JJ, Fisher GJ. Matrix-degrading metalloproteinases in photoaging. J Investig Dermatol Symp Proc. 2009;14(1):20-4

10. Ishida T, Sakaguchi I. Protection of human keratinocytes from UVB-induced inflammation using root extract of Lithospermum erythrorhizon. Biol Pharm Bull. 2007;30(5):928-34.

11. Bickers DR, Athar M. Oxidative stress in the pathogenesis of skin disease. J Invest Dermatol. 2006;126(12):2565-75.

12. Röck K, Meusch M, Fuchs N, Tigges J, Zipper P, Fritsche E, et al. Estradiol protects dermal hyaluronan/versican matrix during photoaging by release of epidermal growth factor from keratinocytes. J Biol Chem. 2012;287(24):20056-69.

13. Steinert PM, Marekov $L N$. The proteins elafin, filaggrin, keratin intermediate filaments, loricrin, and small proline-rich proteins 1 and 2 are isodipeptide cross-linked components of the human epidermal cornified cell envelope. J Biol Chem. 1995;270(30):17702-11.

14. Gill SS, Tuteja N. Reactive oxygen species and antioxidant machinery in abiotic stress tolerance in crop plants. Plant Physiol Biochem. 2010;48(12):909-30.

15. Song $J \mathrm{~L}, \mathrm{Gao}$ Y. Protective effects of Lindera coreana on UVB-induced oxidative stress in human $\mathrm{HaCaT}$ keratinocytes. Iran J Pharm Res. 2014;13(4):1369-78.

16. de Beer D, Schulze AE, Joubert E, de Villiers A, Malherbe CJ, Stander MA. Food ingredient extracts of Cyclopia subternata (Honeybush): variation in phenolic composition and antioxidant capacity. Molecules. 2012;17(12):14602-24

17. Kokotkiewicz A, Luczkiewicz M. Honeybush (Cyclopia sp.)-a rich source of compounds with high antimutagenic properties. Fitoterapia. 2009:80(1):3-11.

18. Marnewick JL, van der Westhuizen FH, Joubert E, Swanevelder S, Swart $P$, Gelderblom WC. Chemoprotective properties of rooibos (Aspalathus linearis), honeybush (Cyclopia intermedia) herbal and green and black (Camellia sinensis) teas against cancer promotion induced by fumonisin B1 in rat liver. Food Chem Toxicol. 2009:47(1):220-9.

19. Im AR, Song JH, Lee MY, Yeon SH, Um KA, Chae S. Anti-wrinkle effects of fermented and non-fermented Cyclopia intermedia in hairless mice. BMC Complement Alterna Med. 2014;14:424.

20. Allemann IB, Baumann L. Botanicals in skin care products. Int J Dermatol. 2009;48(9):923-34

21. Stallings AF, Lupo MP. Practical uses of botanicals in skin care. J Clin Aesthet Dermatol. 2009;2(1):36-40

22. Camouse MM, Domingo DS, Swain FR, Conrad EP, Matsui MS, Maes D, et al. Topical application of green and white tea extracts provides protection from solar-simulated ultraviolet light in human skin. Exp Dermatol. 2009;18(6):522-6.

23. Leon AC, Davis LL, Kraemer HC. The role and interpretation of pilot studies in clinical research. J Psychiatr Res. 2011;45(5):626-9.

24. Dai J, Ma H, Fan J, Li Y, Wang J, Ni H, et al. Crude polysaccharide from an anti-UVB cell clone of Bupleurum scorzonerifolium protect $\mathrm{HaCaT}$ cells against UVB-induced oxidative stress. Cytotechnology. 2011;63(6):599-607.

25. Shindo Y. Witt E, Packer L. Antioxidant defense mechanisms in murine epidermis and dermis and their responses to ultraviolet light. J Invest Dermatol. 1993;100(3):260-5.

26. Fisher GJ, Wang ZQ, Datta SC, Varani J, Kang S, Voorhees JJ. Pathophysiology of premature skin aging induced by ultraviolet light. N Engl J Med. 1997;337(20):1419-28. 
27. Tzaphlidou M. The role of collagen and elastin in aged skin: an image processing approach. Micron. 2004;35(3):173-7.

28. Quan T, Little E, Quan H, Voorhees JJ, Fisher GJ. Elevated matrix metalloproteinases and collagen fragmentation in photodamaged human skin: Impact of altered extracellular matrix microenvironment on dermal fibroblast function. J Invest Dermatol. 2013;133(5):1362-6.

29. Jenkins G. Molecular mechanisms of skin ageing. Mech Ageing Dev. 2002;123(7):801-10.

30. Cho S, Kim HH, Lee MJ, Lee S, Park CS, Nam SJ, et al. Phosphatidylserine prevents UV-induced decrease of type I procollagen and increase of MMP-1 in dermal fibroblasts and human skin in vivo. J Lipid Res. 2008;49(6):1235-45.

31. Hwang E, Sun ZW, Lee TH, Shin HS, Park SY, Lee DG, et al. Enzyme-processed Korean Red Ginseng extracts protects against skin damage induced by UVB irradiation in hairless mice. J Ginseng Res. 2013;37(4):425-34.

32. Bosset $\mathrm{S}$, Bonnet-Duquennoy M, Barré $\mathrm{P}$, Chalon A, Lazou K, Kurfurst R, et al. Decreased expression of keratinocyte beta1 integrins in chronically sun-exposed skin in vivo. Br J Dermatol. 2003;148(4):770-8.

33. Rawlings AV, Matts PJ. Stratum corneum moisturization at the molecular level: an update in relation to the dry skin cycle. J Invest Dermatol. 2005:124(6):1099-110.

34. Bernerd F, Asselineau D. Successive alteration and recovery of epidermal differentiation and morphogenesis after specific UVB-damages in skin reconstructed in vitro. Dev Biol. 1997;183(2):123-38.

35. Lee C, Park GH, Ahn EM, Park Cl, Jang JH. Sargassum fulvellum protects $\mathrm{HaCaT}$ cells and BALB/c mice from UVB-induced proinflammatory responses. Evid Based Complement Alternat Med. 2013;2013:747846.

36. Kirnbauer R, Köck A, Neuner P, Förster E, Krutmann J, Urbanski A, et al. Regulation of epidermal cell interleukin-6 production by UV light and corticosteroids. J Invest Dermatol. 1991;96(4):484-9.

37. Fisher GJ, Talwar HS, Lin J, Lin P, McPhillips F, Wang Z, et al. Retinoic acid inhibits induction of $\mathrm{c}$-Jun protein by ultraviolet radiation that occurs subsequent to activation of mitogen-activated protein kinase pathways in human skin in vivo. J Clin Invest. 1998;101(6):1432-40.

\section{Submit your next manuscript to BioMed Central and we will help you at every step:}

- We accept pre-submission inquiries

- Our selector tool helps you to find the most relevant journal

- We provide round the clock customer support

- Convenient online submission

- Thorough peer review

- Inclusion in PubMed and all major indexing services

- Maximum visibility for your research

Submit your manuscript at www.biomedcentral.com/submit

) Biomed Central 